\title{
Predictors of pulmonary rehabilitation completion in the UK
}

\author{
Philip W. Stone $\mathbb{0}^{1}$, Katherine Hickman², Michael C. Steiner ${ }^{3}$, \\ C. Michael Roberts ${ }^{4,5,6}$, Jennifer K. Quint (1) ${ }^{1,7}$ and Sally J. Singh $h^{3,7}$
}

Affiliations: ${ }^{1}$ National Heart and Lung Institute, Imperial College London, London, UK. ${ }^{2}$ West Yorkshire and Harrogate Health and Care Partnership, Bradford, UK. ${ }^{3}$ NIHR Leicester Respiratory Biomedical Research Centre, Dept of Respiratory Sciences, University of Leicester, Leicester, UK. ${ }^{4}$ UCLPartners, London, UK. ${ }^{5}$ Clinical Quality Improvement Dept, Royal College of Physicians, London, UK. ${ }^{6}$ Institute of Population Health Sciences, Queen Mary University of London, London, UK. ${ }^{7}$ These authors contributed equally.

Correspondence: Philip W. Stone, National Heart and Lung Institute, Emmanuel Kaye Building, 1B Manresa Road, London, SW3 6LR, UK. E-mail: p.stonedimperial.ac.uk

\section{ABSTRACT}

Introduction: Pulmonary rehabilitation has been shown to improve dyspnoea, fatigue, quality of life and exercise capacity in individuals with chronic obstructive pulmonary disease (COPD). Our aim was to determine the characteristics of people with COPD associated with completion of pulmonary rehabilitation.

Methods: This was a cross-sectional analysis of 7060 people with COPD enrolled in pulmonary rehabilitation between January 1, 2017 and March 31, 2017. Data were from a UK national audit of COPD care. Factors associated with pulmonary rehabilitation completion were determined using mixed effects logistic regression with a random intercept for pulmonary rehabilitation service. Factors chosen for assessment based on clinical judgement and data availability were age, sex, country, socioeconomic status, body mass index, referral location, programme type, start within 90 days, smoking status, oxygen therapy, Global Initiative for Chronic Obstructive Lung Disease (GOLD) stage, Medical Research Council (MRC) dyspnoea grade, any exercise test and any health status questionnaire.

Results: 4635 (66\%) people with COPD completed a pulmonary rehabilitation programme. People that were aged $\geqslant 60$ years, resident in Wales, referred within 90 days, an ex- or never-smoker, received an exercise test, or received a health status questionnaire had significantly greater odds of completing pulmonary rehabilitation. People that were in the most deprived quintile, underweight or very severely obese, enrolled in a rolling rather than a cohort programme, had a higher GOLD stage and had a higher MRC grade had significantly lower odds of completing pulmonary rehabilitation.

Conclusions: People with COPD were more likely to complete pulmonary rehabilitation when best practice guidelines were followed. People with more severe COPD symptoms and those enrolled in rolling rather than cohort programmes were less likely to complete pulmonary rehabilitation. Referring people with COPD in the earlier stages of disease, ensuring programmes follow best practice guidelines and favouring cohort over rolling programmes could improve rates of pulmonary rehabilitation completion.

@ERSpublications

Referring people with COPD to pulmonary rehabilitation (PR) in the earlier stages of disease, ensuring PR programmes follow best practice guidelines and favouring cohort over rolling PR programmes could improve rates of PR completion https://bit.ly/34BfeEb

Cite this article as: Stone PW, Hickman K, Steiner MC, et al. Predictors of pulmonary rehabilitation completion in the UK. ERJ Open Res 2021; 7: 00509-2020 [https://doi.org/10.1183/23120541.005092020].

This article has supplementary material available from openres.ersjournals.com

Received: 20 July 2020 | Accepted after revision: 22 Oct 2020

Copyright $\odot$ ERS 2021. This article is open access and distributed under the terms of the Creative Commons Attribution Non-Commercial Licence 4.0 


\section{Introduction}

Pulmonary rehabilitation has been shown to improve dyspnoea, fatigue, quality of life and exercise capacity in individuals with chronic obstructive pulmonary disease (COPD) [1,2]. The quality of evidence for these benefits has been declared such that no further randomised controlled trials (RCTs) comparing pulmonary rehabilitation and usual care are required to demonstrate its benefits $[1,3]$.

While the strength of evidence for the benefits of pulmonary rehabilitation is high and the referral criteria are well defined [4,5], the proportion of people with COPD being referred to and completing pulmonary rehabilitation remains low. In the UK, most pulmonary rehabilitation referrals are from primary care $[6,7]$. However, between 2004 and 2014 only 9\% of eligible people with COPD in England were referred to pulmonary rehabilitation from primary care [8], and in the English and Welsh pulmonary rehabilitation audit it was found that only $\sim 42 \%$ of those referred to pulmonary rehabilitation completed a programme [6].

In the UK, pulmonary rehabilitation programmes have a median (interquartile range) session count of 12 (12-14) [7] and are predominantly (98.2\%) centre (community or acute unit) based, with $1.3 \%$ of programmes being home based and the remaining $0.5 \%$ being delivered in both. $50 \%$ of programmes are rolling based (patients start and end at different times) and $48 \%$ are cohort based (all patients start and end at the same time) [7]. 5\% of programmes require patients to stop smoking before they can enrol [7].

Previous large studies of predictors of pulmonary rehabilitation completion have either only presented unadjusted results [9], been limited to just one city [10-14] or used an RCT population [15] that is not representative of all potential pulmonary rehabilitation referrals. We therefore aimed to use a national audit cohort to determine the characteristics of people with COPD associated with completion of pulmonary rehabilitation. This would be the largest cohort assessed to date and allow us to discover individuals that require better targeting.

\section{Material and methods \\ Database/population}

To investigate patient factors associated with pulmonary rehabilitation completion, we used data from the National COPD Audit Programme (NCAP) 2017 clinical audit of pulmonary rehabilitation services in England and Wales. The audit identified 195 pulmonary rehabilitation services across England and Wales, and invited them to participate in the audit which ran from January 3, 2017 to March 31, 2017. 184 (94\%) chose to participate; reasons for nonparticipation were lack of resources to complete data collection and entry, and no patients receiving initial assessment during the audit period. From these 184 pulmonary rehabilitation services, 9427 patients were eligible to contribute to the audit (patients with a primary diagnosis of COPD who were assessed for or began pulmonary rehabilitation during the audit period), 8769 patients were approached for consent and 7896 (90\% of those approached) gave their consent to contribute to the audit. Patient data were entered into a bespoke web tool created for the audit and data were stored in a secure data centre. Pulmonary rehabilitation services were allowed to complete data entry until July 31, 2017. This was 3 months after the end of the study period to ensure that all patients were followed-up to completion. After data cleaning by the audit team, a dataset of 7476 COPD patients who had been assessed for or began pulmonary rehabilitation between January 3, 2017 and March 31, 2017 at one of 184 pulmonary rehabilitation services in England and Wales was established. Full details of the audit and the methodology used to create the dataset can be found in the NCAP audit data report [7].

\section{Variables}

The outcome of the analysis, i.e. completion of pulmonary rehabilitation, was defined as any enrolled patient that received a discharge assessment. 14 exposures (age, sex, country, socioeconomic status (SES), body mass index (BMI), referral location, programme type, start within 90 days, smoking status, oxygen therapy, Global Initiative for Chronic Obstructive Lung Disease (GOLD) stage, Medical Research Council (MRC) dyspnoea grade, any exercise test and any health status questionnaire) were used as potential predictors of pulmonary rehabilitation completion. Exposures were chosen based on clinical judgement and data availability. People without age data and people aged $<35$ years at initial appointment for pulmonary rehabilitation were excluded as the accepted definition of COPD in the UK requires patients to be $\geqslant 35$ years old [4]. Additionally, people that did not enrol on a pulmonary rehabilitation programme were excluded to remove unsuitability or lack of motivation as factors for noncompletion.

SES was defined as quintile of either English Index of Multiple Deprivation (IMD) 2015 or Welsh Index of Multiple Deprivation (WIMD) 2014, derived using the patient's home post code (note that IMD and WIMD derivation was performed prior to our receipt of data so that potentially identifying information such as post code was not made available to us). IMD and WIMD are measures of deprivation that rank the relative deprivation between small areas (or neighbourhoods) of England and Wales, respectively. Values for IMD and WIMD are derived by assessing how deprived an area is in the domains of income, 
employment, education, health, crime, housing, environment and access to services [16, 17]. Country of residence was defined based on the presence of either an IMD (England) or WIMD (Wales) value. Further definitions of variables can be found in the supplementary material.

\section{Statistical analysis}

All data management and statistical analyses were performed using Stata version 15 (StataCorp, College Station, TX, USA). Data were first summarised using means and proportions where appropriate. Age was discretised to produce a categorical variable as its relationship with pulmonary rehabilitation completion was nonlinear. MRC grades 1 and 2 were combined as very few patients were grade 1 . Where variables had $\leqslant 5 \%$ missing data, complete-case analysis was used, otherwise additional missing data categories were added to preserve sample size. To account for clustering of patients at the pulmonary rehabilitation service level, mixed effects logistic regression (Stata "xtlogit" command, "RE" option) was used to investigate the association between each of the 14 exposures and pulmonary rehabilitation completion with a random intercept for pulmonary rehabilitation service. Odds ratios with $95 \%$ confidence intervals were generated for each exposure.

After univariate analyses, minimally adjusted models were created by adding the a priori confounders age, sex and SES to the mixed effects logistic regression models to produce adjusted odds ratios and $95 \%$ confidence intervals for each predictor. Finally, mutually adjusted mixed effects logistic regression models were created using all predictors. These represent our maximally adjusted models. Statistical significance of predictors in the mutually adjusted models was determined using the likelihood ratio test with $\mathrm{p}<0.05$ regarded as significant. Multicollinearity of predictors in the mutually adjusted models was assessed using the Stata "collin" command. A variance inflation factor (VIF) of 10 was defined as indicating problematic multicollinearity. All variables in both models had VIFs well below 10, indicating multicollinearity was not an issue in the final models. Odds ratio graphs were generated using coefplot [18].

Sensitivity analyses were performed using complete-case analysis instead in the mutually adjusted models, where the additional missing data categories were not included. Sensitivity analyses were also performed separately in English and Welsh patients to see the effect of combining IMD and WIMD quintiles.

\section{Ethical approval}

The Healthcare Quality Improvement Partnership (HQIP) is data controller for National Clinical Audit and Patient Outcomes Programme projects. An HQIP extended output scope form was completed for both of the audit datasets used in this analysis. Formal approval from the HQIP Data Access Request Group was not required as both datasets use de-identified pseudonymised data for a purpose deemed to be in line with primary audit data collection [19]. Formal consent to use their data to produce academic papers was collected from patients who contributed to the pulmonary rehabilitation clinical audit dataset.

\section{Results}

Of the 7476 patients included in the audit dataset, 413 (5.52\%) were excluded due to not enrolling in a pulmonary rehabilitation programme, two $(0.03 \%)$ were excluded for not having any age data and one $(0.01 \%)$ was excluded for being $<35$ years of age. Of the 7060 patients that enrolled on a pulmonary rehabilitation programme, 4635 (66\%) completed pulmonary rehabilitation (table 1 and supplementary table S1). People <60 years of age had the lowest proportion (50.2\%) of pulmonary rehabilitation completion, and Welsh (76.6\%) and the least deprived quintile of patients $(75.6 \%)$ had the highest proportion of completion. Patients that competed pulmonary rehabilitation attended an average of $92 \%$ of their scheduled sessions, whereas those that did not complete pulmonary rehabilitation attended an average of $32 \%$ of their scheduled sessions.

Crude, minimally adjusted and mutually adjusted odds ratios for completion of pulmonary rehabilitation are shown in table 2 . In the analysis adjusted for age, sex and deprivation (minimally adjusted), patients that were more deprived, underweight, very severely obese, enrolled in a rolling rather than cohort programme, receiving oxygen at home, had a higher GOLD stage or higher MRC grade had lower odds of completing pulmonary rehabilitation, and patients that were aged $\geqslant 60$ years, lived in Wales, started pulmonary rehabilitation within 90 days of referral, ex-smokers, never-smokers and received any exercise test or health status questionnaire at initial assessment had higher odds of completing pulmonary rehabilitation.

After mutual adjustment of the predictor variables, significant predictors of pulmonary rehabilitation completion were age $(p<0.0001)$, country of residence $(p=0.0197)$, deprivation $(p=0.0012)$, BMI $(\mathrm{p}=0.0028)$, programme type $(\mathrm{p}=0.0004)$, starting pulmonary rehabilitation within 90 days of referral $(\mathrm{p}=0.0051)$, smoking status $(\mathrm{p}<0.0001)$, GOLD stage $(\mathrm{p}=0.0362)$, MRC grade $(\mathrm{p}<0.0001)$, receipt of an exercise test at initial assessment $(\mathrm{p}<0.0001)$ and receipt of a health status questionnaire at initial 


\begin{tabular}{|c|c|c|}
\hline & $\begin{array}{l}\text { Did not complete } \\
\text { pulmonary rehabilitation }\end{array}$ & $\begin{array}{l}\text { Completed pulmonary } \\
\text { rehabilitation }\end{array}$ \\
\hline Age years & $N=2425$ & $N=4635$ \\
\hline $35-59$ & 509 (49.8) & $514(50.2)$ \\
\hline $60-64$ & $369(40.1)$ & 552 (59.9) \\
\hline $65-69$ & 469 (32.7) & $964(67.3)$ \\
\hline $70-74$ & 465 (28.7) & 1154 (71.3) \\
\hline $75-79$ & $353(30.4)$ & $810(69.7)$ \\
\hline$\geqslant 80$ & $260(28.9)$ & $641(71.1)$ \\
\hline Sex & $N=2425$ & $N=4635$ \\
\hline Male & $1210(32.7)$ & $2488(67.3)$ \\
\hline Female & $1215(36.1)$ & $2147(63.9)$ \\
\hline Country of residence & $N=2408$ & $N=4587$ \\
\hline England & 2347 (34.9) & $4387(65.2)$ \\
\hline Wales & $61(23.4)$ & $200(76.6)$ \\
\hline $\begin{array}{l}\text { Quintile of English or Welsh Index of } \\
\text { Multiple Deprivation }\end{array}$ & $N=2408$ & $\mathrm{~N}=4587$ \\
\hline 1 (most deprived) & $815(45.1)$ & 993 (54.9) \\
\hline 2 & $517(34.5)$ & $980(65.5)$ \\
\hline 3 & $447(32.1)$ & 946 (67.9) \\
\hline 4 & $372(29.9)$ & $873(70.1)$ \\
\hline 5 (least deprived) & $257(24.4)$ & $795(75.6)$ \\
\hline $\begin{array}{l}\text { Quintile of } 2015 \text { English Index of Multiple } \\
\text { Deprivation }\end{array}$ & $N=2347$ & $N=4387$ \\
\hline 1 (most deprived) & $797(45.5)$ & 953 (54.5) \\
\hline 2 & $504(35.0)$ & $936(65.0)$ \\
\hline 3 & $434(32.5)$ & 900 (67.5) \\
\hline 4 & 361 (30.3) & 829 (69.7) \\
\hline 5 (least deprived) & $251(24.6)$ & $769(75.4)$ \\
\hline $\begin{array}{l}\text { Quintile of } 2014 \text { Welsh Index of Multiple } \\
\text { Deprivation }\end{array}$ & $N=61$ & $\mathrm{~N}=200$ \\
\hline 1 (most deprived) & $18(31.0)$ & $40(69.0)$ \\
\hline 2 & 13 (22.8) & 44 (77.2) \\
\hline 3 & $13(22.0)$ & $46(78.0)$ \\
\hline 4 & $11(20.0)$ & $44(80.0)$ \\
\hline 5 (least deprived) & $6(18.8)$ & $26(81.3)$ \\
\hline BMI & $N=2425$ & $N=4635$ \\
\hline Underweight & $108(46.4)$ & $125(53.7)$ \\
\hline Healthy & 507 (33.1) & $1026(66.9)$ \\
\hline Overweight & $469(30.8)$ & 1056 (69.3) \\
\hline Obese & $484(33.2)$ & $976(66.9)$ \\
\hline Very severely obese & $102(41.6)$ & 143 (58.4) \\
\hline No data & $755(36.6)$ & 1309 (63.4) \\
\hline $\begin{array}{l}\text { Location of referral to pulmonary } \\
\text { rehabilitation }\end{array}$ & $\mathrm{N}=2342$ & $N=4513$ \\
\hline Community & 1535 (32.8) & 3140 (67.2) \\
\hline Hospital & 807 (37.0) & $1373(63.0)$ \\
\hline Programme type & $N=2333$ & $N=4547$ \\
\hline Cohort & 782 (28.3) & 1984 (71.7) \\
\hline Rolling & $1551(37.7)$ & 2563 (62.3) \\
\hline Referral to start of pulmonary rehabilitation & $\begin{array}{l}N=2373 \\
1420(33.7)\end{array}$ & $\mathrm{N}=4591$ \\
\hline Smoking status & $\mathrm{N}=2352$ & $\mathrm{~N}=4504$ \\
\hline Current smoker & $742(49.4)$ & $759(50.6)$ \\
\hline Ex-smoker & $1493(30.4)$ & $3425(69.6)$ \\
\hline Never-smoker & 117 (26.8) & $320(73.2)$ \\
\hline $\begin{array}{l}\text { Patient receiving oxygen therapy at home at } \\
\text { the time of initial assessment }\end{array}$ & $\begin{array}{l}N=2398 \\
179(36.8)\end{array}$ & $\begin{array}{l}N=4605 \\
308(63.2)\end{array}$ \\
\hline
\end{tabular}




\begin{tabular}{|c|c|c|}
\hline & $\begin{array}{l}\text { Did not complete } \\
\text { pulmonary rehabilitation }\end{array}$ & $\begin{array}{l}\text { Completed pulmonary } \\
\text { rehabilitation }\end{array}$ \\
\hline GOLD stage & $N=2425$ & $N=4635$ \\
\hline 1 & $151(28.5)$ & $378(71.5)$ \\
\hline 2 & $660(32.5)$ & $1368(67.5)$ \\
\hline 3 & 440 (32.5) & $912(67.5)$ \\
\hline 4 & $141(36.1)$ & 250 (63.9) \\
\hline No data & $1033(37.4)$ & $1727(62.6)$ \\
\hline MRC grade & $N=2425$ & $\mathrm{~N}=4635$ \\
\hline 1 or 2 & $293(25.6)$ & $852(74.4)$ \\
\hline 3 & $830(32.6)$ & $1714(67.4)$ \\
\hline 4 & $821(37.6)$ & $1360(62.4)$ \\
\hline 5 & $255(46.4)$ & $295(53.6)$ \\
\hline No data & 226 (35.3) & 414 (64.7) \\
\hline Any of ISWT, ESWT or 6MWT & $N=2425$ & $N=4635$ \\
\hline & 2185 (32.8) & $4478(67.2)$ \\
\hline Any of SGRQ, CRQ or CAT & $N=2421$ & $N=4627$ \\
\hline & 2018 (31.9) & $4310(68.1)$ \\
\hline \multicolumn{3}{|c|}{$\begin{array}{l}\text { Data are presented as n (\%), unless otherwise stated; percentages are row percentages. BMI: body mass } \\
\text { index; GOLD: Global Initiative for Chronic Obstructive Lung Disease; MRC: Medical Research Council; } \\
\text { ISWT: incremental shuttle walk test; ESWT: endurance shuttle walk test; 6MWT: 6-min walk test; SGRQ: } \\
\text { St George's Respiratory Questionnaire; CRQ: Chronic Respiratory Questionnaire; CAT: COPD Assessment } \\
\text { Test. Further definitions of variables can be found in the supplementary material. }\end{array}$} \\
\hline
\end{tabular}

assessment $(\mathrm{p}<0.0001)$ (table 2$)$. In the mutually adjusted analysis, patients that were aged $\geqslant 60$ years, lived in Wales, started pulmonary rehabilitation within 90 days of referral, ex-smokers, never-smokers, received any exercise test or received any health status questionnaire at initial assessment had higher odds of completing pulmonary rehabilitation. Patients that were in the most deprived quintile, underweight, very severely obese, enrolled in a rolling rather than a cohort programme, had a higher GOLD stage or had a higher MRC grade had lower odds of completing pulmonary rehabilitation (figure 1 and table 2).

\section{Sensitivity analyses}

Results of analyses using English deprivation data only were very similar to analyses using combined English and Welsh deprivation data. Analysis using Welsh deprivation data only was not possible due to the small sample size. Complete-case analysis resulted in the predictor variables of programme type ( $\mathrm{p}=0.0562)$, starting pulmonary rehabilitation within 90 days of referral $(\mathrm{p}=0.0559)$ and GOLD stage ( $\mathrm{p}=0.3820)$ no longer being statistically significant (supplementary table S2).

\section{Discussion}

Age, country of residence, deprivation, BMI, programme type, starting pulmonary rehabilitation within 90 days of referral, smoking status, GOLD stage, MRC grade, receipt of an exercise test at initial assessment and receipt of a health status questionnaire at initial assessment were all associated with completion of pulmonary rehabilitation. Patients who were aged $\geqslant 60$ years, resident in Wales, started pulmonary rehabilitation within 90 days of referral, ex- or never-smokers (relative to current smokers), completed an exercise test at initial assessment and completed a health status questionnaire at initial assessment were more likely to complete pulmonary rehabilitation. Patients who were in the most deprived quintile of IMD/WIMD, underweight or very severely obese (relative to a healthy weight), enrolled in a rolling programme (rather than a cohort programme), had a higher GOLD stage and had a higher MRC grade were less likely to complete pulmonary rehabilitation.

It is concerning that those for whom the service is specifically directed, i.e. MRC grades 3-5, are less likely to complete than those who are less symptomatic from their COPD. This may be because patients with more severe symptoms are more likely to be hospitalised or die before they can complete their pulmonary rehabilitation programme. It may also indicate that we are not delivering the optimum format of pulmonary rehabilitation for more symptomatic patients to facilitate completion and that we could perhaps deliver pulmonary rehabilitation to patients with lower MRC grades so that they are able to complete their programme before their symptoms progress to a level that makes completion more difficult. This group of patients is not routinely referred and falls outside the scope of practice identified in national 
TABLE 2 Odds ratios for completion of pulmonary rehabilitation in chronic obstructive pulmonary disease (COPD) patients that enrolled in a pulmonary rehabilitation programme by patient characteristic

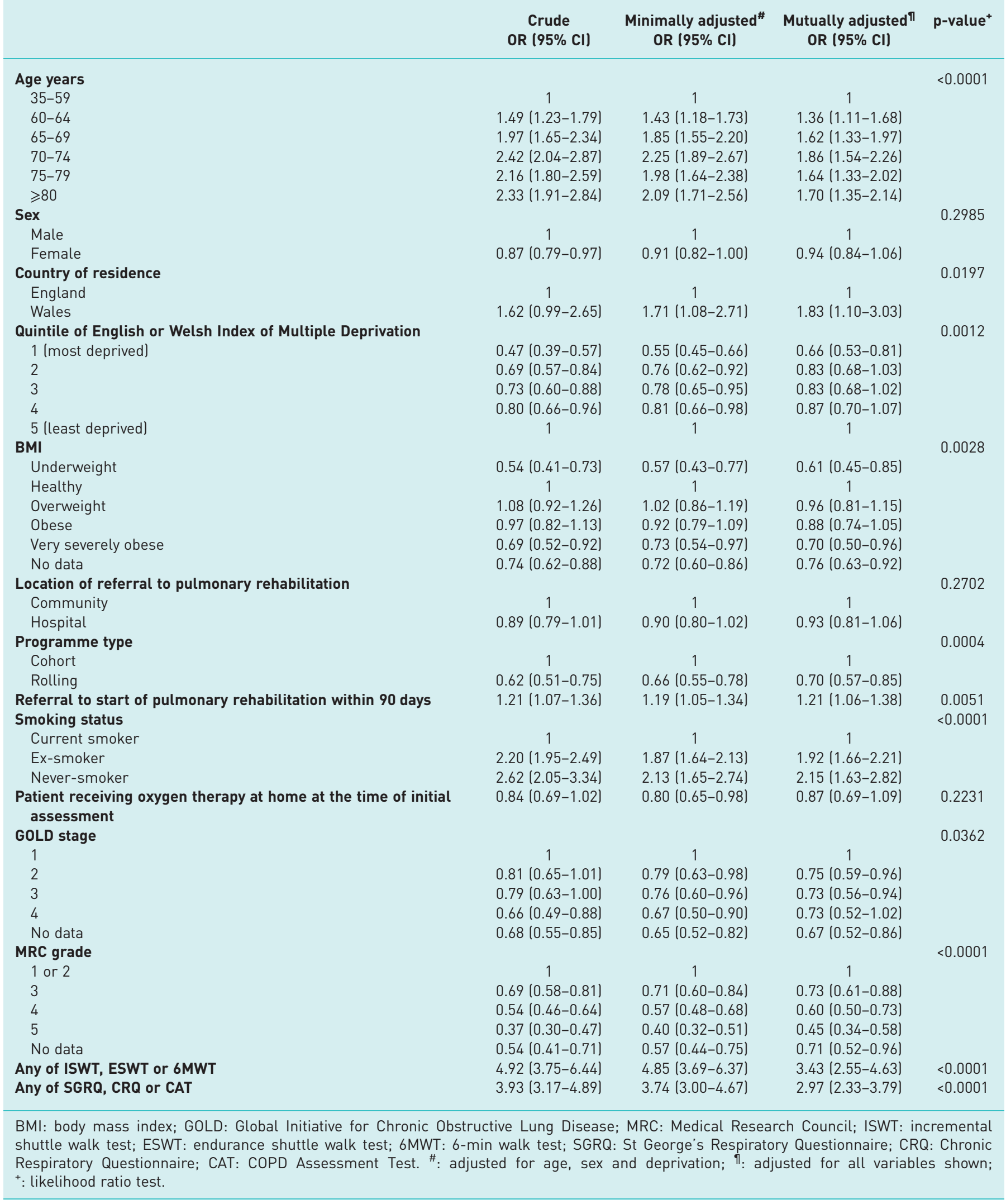




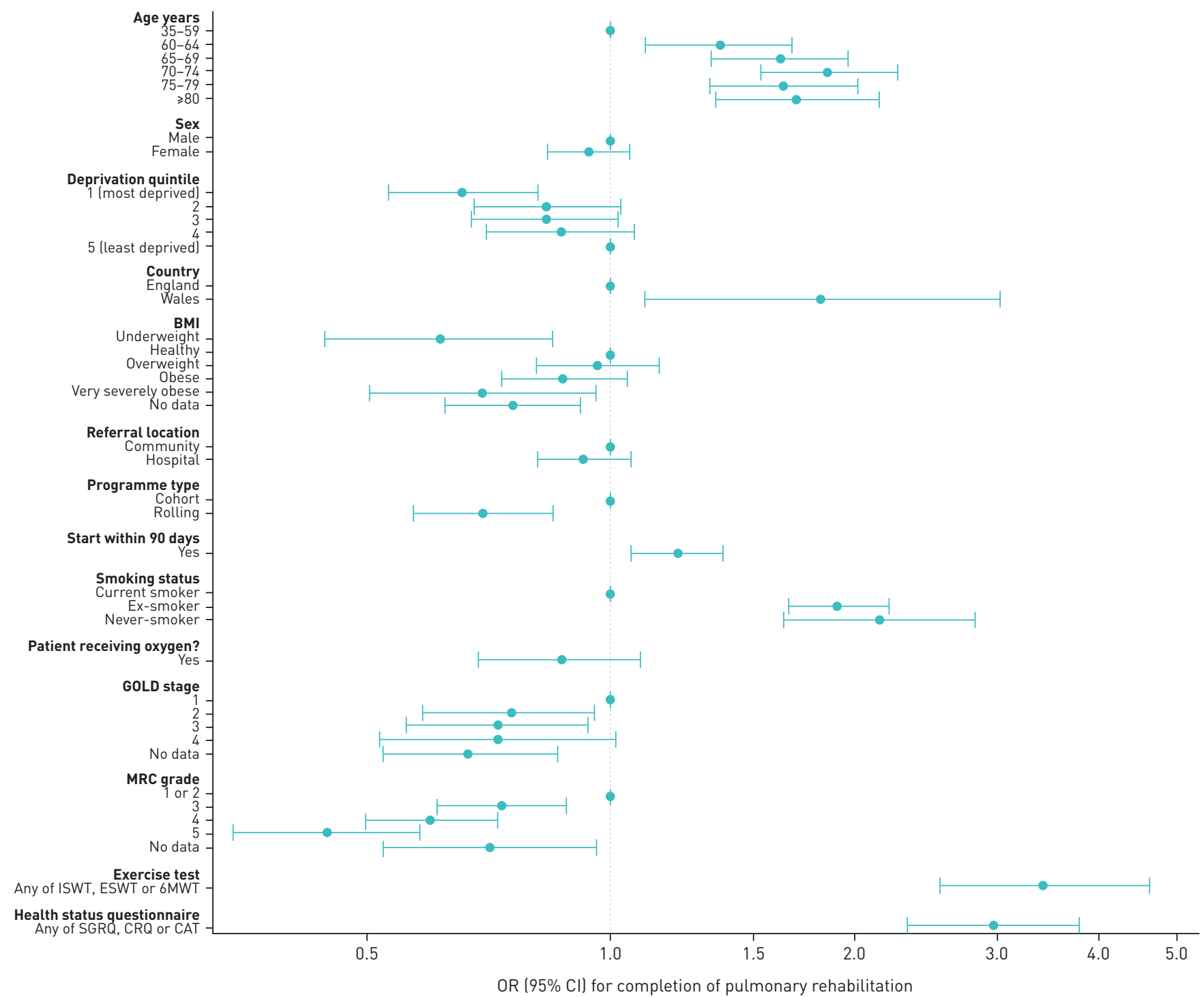

FIGURE 1 Plot showing mutually adjusted odds ratios for completion of pulmonary rehabilitation in chronic obstructive pulmonary disease (COPD) patients that enrolled in a pulmonary rehabilitation programme by patient characteristics. BMI: body mass index; GOLD: Global Initiative for Chronic Obstructive Lung Disease; MRC: Medical Research Council; ISWT: incremental shuttle walk test; ESWT: endurance shuttle walk test; 6MWT: 6-min walk test; SGRQ: St George's Respiratory Questionnaire; CRQ: Chronic Respiratory Questionnaire; CAT: COPD Assessment Test.

guidance, with some services not commissioned to provide pulmonary rehabilitation to patients with an MRC grade <3 [4]. Increased likelihood of completion in patients that started pulmonary rehabilitation within 90 days of referral or completed an exercise test or health status questionnaire at initial assessment seems to indicate that there is an increased likelihood of completion in services that adhere to national and international process guidance $[20,21]$.

Several previous studies have examined patient characteristics associated with pulmonary rehabilitation completion. The most frequent association found is between smoking status and completion, either in the form of ex-smoking relative to current smoking [12, 14, 22-25] (as in this study), smoking pack-years [26] or time since smoking cessation [11]. Previous authors have suggested this could be due to the same lack of motivation preventing both smoking cessation and adherence to a pulmonary rehabilitation programme $[11,14,22-24]$. Qualitative studies also list lack of motivation as a key reason for not attending pulmonary rehabilitation [27, 28]. Sex and referral location were variables that have also been associated with pulmonary rehabilitation completion in previous studies, but no such association was found in this study $[10,14,25]$. Similar to our study, Накаму et al. [29] found that patients that had a practice test before their exercise test were $17 \%$ more likely to complete pulmonary rehabilitation.

One novel association with failure to complete pulmonary rehabilitation in this study is enrolment on a rolling programme. It is possible that patients have a greater sense of camaraderie in cohort programmes, 
supporting, encouraging and motivating each other to keep going and complete the programme. HoGG et al. [10] examined this relationship but found no association between programme type and pulmonary rehabilitation completion; however, it was only examined in unadjusted analysis. Alternatively, this finding could be due to the design of the audit programme. The audit ran for a period of 3 months and the participating pulmonary rehabilitation services had until 4 months after the audit period to complete their data entry into the audit system. In contrast, HogG et al. [10] ran their study for a period of 2 years, meaning participants entering a rolling programme towards the end of the study (and therefore potentially not having complete follow-up) would have comprised a lower proportion of the analysed cohort.

Other associations with pulmonary rehabilitation completion found in previous studies as well as this study have been MRC grade [10, 23, 28], forced expiratory volume in 1 s percent of predicted $[11,14,15]$ (used as GOLD stage in this study), SES $[9,10,30]$ and age $[11,25]$. As in this study, higher age [11] has previously been linked with pulmonary rehabilitation completion, but so has lower age [25]. As SeLZLER et al. [11] suggest, work commitments could be a reason for higher age being associated with completion as younger patients may find it harder to allocate time for pulmonary rehabilitation sessions. This is an issue raised by some patients in qualitative studies [27, 31]. It is also worth noting the nonlinear association with age in this study: up to age 70-74 years patients become increasingly more likely to complete, but at $\geqslant 75$ years of age likelihood of completion decreases (although there is no significant difference between any of the $\geqslant 60$ years age groups), a possible indication that completion is less likely in the oldest participants.

\section{Strengths and limitations}

The strength of this study comes from its size and generalisability. It examines completion for 7060 patients enrolled in pulmonary rehabilitation programmes covering nearly all of England and Wales, and as national audit data, patients included in the study are representative of pulmonary rehabilitation users.

This analysis is, however, not without limitations. IMD/WIMD are not perfect definitions of SES, as they only signify the deprivation of an area in which a person lives, not how deprived that person is. This is likely to bias results towards the null hypothesis for SES as the deprivation of a local population will appear more homogenous. Ethnicity would have been a desirable predictor to include in our analysis; however, this was unavailable in the audit dataset and we suspect that the analysed cohort would be very homogenous with regard to ethnicity, limiting generalisability to more diverse populations. Missing data were also an issue; in sensitivity analysis using complete-case rather than including missing data in its own category (the main analysis), programme type, starting pulmonary rehabilitation within 90 days of referral and GOLD stage were not significantly associated with pulmonary rehabilitation completion (unlike in the main analysis). The reason for this lack of association in complete-case analysis could be due to reduced power (the sample size more than halved) or it could be that the missing data categories have biased the results (equally, excluding missing data could bias results). The fact that the p-values were borderline significant for programme type and starting pulmonary rehabilitation within 90 days does perhaps indicate that power was the issue in complete-case analysis. As completion of pulmonary rehabilitation was quite common $(66 \%$ completed), odds ratios are unlikely to approximate risk ratios and may overestimate likelihood of completion. Finally, several significance tests were performed in this study, increasing the probability that some of our significant results are chance findings.

\section{Conclusions}

People with COPD were more likely to complete pulmonary rehabilitation when best practice guidelines were followed. People with more severe COPD symptoms, those that were likely to be less motivated and people enrolled in a rolling rather than a cohort programme were less likely to complete pulmonary rehabilitation. This has potential implications for the future design of pulmonary rehabilitation programmes, i.e. earlier referral and cohort programmes may need to be prioritised. Useful further work would be to compare outcomes between cohort and rolling programmes. This would help inform whether swift programme entry or programme type should be prioritised.

Acknowledgements: We would like to thank the Healthcare Quality Improvement Partnership for commissioning the National COPD Audit Programme, the National COPD Audit Programme team, NHS Wales Informatics Service and everyone who collected data for the audit programme. Unadjusted analyses from this work have previously been presented in abstract form at the 2019 American Thoracic Society International Conference (Dallas, TX, USA).

Author contributions: P.W. Stone performed the analysis and wrote the first draft of the manuscript. All other authors contributed to the design, interpretation and subsequent drafts. J.K. Quint is the guarantor.

Conflict of interest: P.W. Stone reports that he is part of the analysis team for the National Asthma and COPD Audit Programme and his university receives funding for that from the Royal College of Physicians. K. Hickman has nothing to disclose. M.C. Steiner reports advisory board fees from GlaxoSmithKline and nonfinancial support for travel to an 
international conference from Boehringer Ingelheim, outside the submitted work. C.M. Roberts reports personal fees from AstraZeneca and Pfizer for nonpromotional educational seminars for primary care staff on the relevance of audit findings, outside the submitted work. J.K. Quint reports that she is the analysis lead for the National Asthma and COPD Audit Programme and her university receives funding for that from the Royal College of Physicians; and grants and personal fees from AstraZeneca, Bayer, Boehringer Ingelheim, Chiesi and GlaxoSmithKline, and grants from the Medical Research Council and The Health Foundation, outside the submitted work. S.J. Singh has nothing to disclose.

\section{References}

1 McCarthy B, Casey D, Devane D, et al. Pulmonary rehabilitation for chronic obstructive pulmonary disease. Cochrane Database Syst Rev 2015: 2; CD003793.

2 Steiner M, McMillan V, Lowe D, et al. Pulmonary Rehabilitation: Beyond Breathing Better. National Chronic Obstructive Pulmonary Disease (COPD) Audit Programme: Outcomes from the Clinical Audit of Pulmonary Rehabilitation Services in England 2015. Results and Data Analysis. London, Royal College of Physicians, 2017.

3 Lacasse Y, Cates CJ, McCarthy B, et al. This Cochrane Review is closed: deciding what constitutes enough research and where next for pulmonary rehabilitation in COPD. Cochrane Database Syst Rev 2015: 11; ED000107.

$4 \quad$ National Institute for Health and Care Excellence. Chronic Obstructive Pulmonary Disease in Over 16s: Diagnosis and Management. Recommendations. NICE Guideline (NG115). London, NICE, 2019.

5 Bolton CE, Bevan-Smith EF, Blakey JD, et al. British Thoracic Society guideline on pulmonary rehabilitation in adults: accredited by NICE. Thorax 2013; 68: Suppl. 2, ii1-ii30.

6 Steiner M, Holzhauer-Barrie J, Lowe D, et al. Pulmonary Rehabilitation: Steps to Breathe Better. National Chronic Obstructive Pulmonary Disease (COPD) Audit Programme: Clinical Audit of Pulmonary Rehabilitation services in England and Wales 2015. National Clinical Audit Report. London, Royal College of Physicians, 2016.

7 Steiner MC, McMillan V, Lowe D, et al. Pulmonary Rehabilitation: An Exercise in Improvement. National Chronic Obstructive Pulmonary Disease (COPD) Audit Programme: Clinical and Organisational Audit of Pulmonary Rehabilitation Services in England and Wales 2017. Clinical Audit Data Analysis and Results. London, Royal College of Physicians, 2018.

8 Moore E, Newson R, Joshi M, et al. Effects of pulmonary rehabilitation on exacerbation number and severity in people with COPD: an historical cohort study using electronic health records. Chest 2017; 152: 1188-1202.

9 Steiner MC, Lowe D, Beckford K, et al. Socioeconomic deprivation and the outcome of pulmonary rehabilitation in England and Wales. Thorax 2017; 72: 530-537.

10 Hogg L, Garrod R, Thornton H, et al. Effectiveness, attendance, and completion of an integrated, system-wide pulmonary rehabilitation service for COPD: prospective observational study. COPD 2012; 9: 546-554

11 Selzler A-M, Simmonds L, Rodgers WM, et al. Pulmonary rehabilitation in chronic obstructive pulmonary disease: predictors of program completion and success. COPD 2012; 9: 538-545.

12 Hayton C, Clark A, Olive S, et al. Barriers to pulmonary rehabilitation: characteristics that predict patient attendance and adherence. Respir Med 2013; 107: 401-407.

13 Boutou AK, Tanner RJ, Lord VM, et al. An evaluation of factors associated with completion and benefit from pulmonary rehabilitation in COPD. BMJ Open Respir Res 2014; 1: e000051.

14 Cassidy S, Turnbull S, Gardani M, et al. Attendance at pulmonary rehabilitation classes: an exploration of demographic, physiological and psychological factors that predict completion of treatment. Chron Respir Dis 2014; 11: 95-102.

15 Fan VS, Giardino ND, Blough DK, et al. Costs of pulmonary rehabilitation and predictors of adherence in the national emphysema treatment trial. COPD 2008; 5: 105-116.

16 Dept for Communities and Local Government. English Indices of Deprivation 2015. 2015. www.gov.uk/ government/statistics/english-indices-of-deprivation-2015 Date last accessed: August 14, 2019.

17 Welsh Government. Welsh Index of Multiple Deprivation (Full Index Update with Ranks): 2014. 2014. https://gov. wales/welsh-index-multiple-deprivation-full-index-update-ranks-2014 Date last accessed: August 14, 2019.

18 Jann B. COEFPLOT: Stata module to plot regression coefficients and other results. 2013. https://ideas.repec.org/c/ boc/bocode/s457686.html Date last accessed: August 28, 2019.

19 Healthcare Quality Improvement Partnership. Accessing NCAPOP data. 2017. www.hqip.org.uk/nationalprogrammes/accessing-ncapop-data Date last accessed: August 15, 2019.

20 British Thoracic Society. Quality Standards for Pulmonary Rehabilitation in Adults. London, BTS, 2014.

21 Rochester CL, Vogiatzis I, Holland AE, et al. An Official American Thoracic Society/European Respiratory Society Policy Statement: Enhancing Implementation, Use, and Delivery of Pulmonary Rehabilitation. Am J Respir Crit Care Med 2015; 192: 1373-1386.

22 Young P, Dewse M, Fergusson W, et al. Respiratory rehabilitation in chronic obstructive pulmonary disease: predictors of nonadherence. Eur Respir J 1999; 13: 855-859.

23 Sabit R, Griffiths TL, Watkins AJ, et al. Predictors of poor attendance at an outpatient pulmonary rehabilitation programme. Respir Med 2008; 102: 819-824.

24 Brown AT, Hitchcock J, Schumann C, et al. Determinants of successful completion of pulmonary rehabilitation in COPD. Int J Chron Obstruct Pulmon Dis 2016; 11: 391-397.

25 McCarron EP, Bailey M, Leonard B, et al. Improving the uptake: barriers and facilitators to pulmonary rehabilitation. Clin Respir J 2019; 13: 624-629.

26 Garrod R, Marshall J, Barley E, et al. Predictors of success and failure in pulmonary rehabilitation. Eur Respir J 2006; 27: 788-794.

27 Keating A, Lee A, Holland AE. What prevents people with chronic obstructive pulmonary disease from attending pulmonary rehabilitation? A systematic review. Chron Respir Dis 2011; 8: 89-99.

28 Sahin $\mathrm{H}, \mathrm{Naz}$ I. Why are COPD patients unable to complete the outpatient pulmonary rehabilitation program? Chron Respir Dis 2018; 15: 411-418.

29 Hakamy A, McKeever TM, Steiner MC, et al. The use of the practice walk test in pulmonary rehabilitation program: National COPD Audit Pulmonary Rehabilitation Workstream. Int J Chron Obstruct Pulmon Dis 2017; 12: $2681-2686$. 
30 Spitzer KA, Stefan MS, Priya A, et al. Participation in pulmonary rehabilitation after hospitalization for chronic obstructive pulmonary disease among medicare beneficiaries. Ann Am Thorac Soc 2018; 16: 99-106.

31 Keating A, Lee AL, Holland AE. Lack of perceived benefit and inadequate transport influence uptake and completion of pulmonary rehabilitation in people with chronic obstructive pulmonary disease: a qualitative study. J Physiother 2011; 57: 183-190. 